\title{
Evaluation of the Results of Endoscopic Release of Plantar Fascia in Cases of Resistant Chronic Heel Pain
}

\author{
Altowijri Albraa Ahmed ${ }^{1}$, Alshareef Hatim Mohammed A ${ }^{2}$, Alhasan Ahmed Hassan A ${ }^{3}$, Mahmoud Ahmed \\ Alqady $^{2}$, Mohammed G Flemban ${ }^{2}$, Alshareef Amer Mohammed A ${ }^{4}$ \& Radhwan Abdulelah Khalii ${ }^{5}$ \\ ${ }^{1}$ University of Tabuk, Faculty of Medicine, Tabuk, KSA \\ ${ }^{2}$ King Fahad Armed Forces Hospital, Jeddah, KSA \\ ${ }^{3}$ University of Jeddah, Faculty Of Medicine, Jeddah, KSA \\ ${ }^{4}$ Ibn Sina National College, Jeddah, Saudi Arabia \\ ${ }^{5}$ Umm Al-Qura University, Makkah, KSA \\ Correspondence: Alshareef Hatim Mohammed A., King Fahad Armed Forces Hospital, Jeddah, KSA.
}

Received: November 13, 2016 Accepted: January 5, 2017 Online Published: January 25, 2017

doi:10.5539/gjhs.v9n3p209～URL: http://dx.doi.org/10.5539/gjhs.v9n3p209

\begin{abstract}
Aim: To evaluate the results of endoscopic release of plantar fascia in resistant cases of heel pain.

Methods: An experimental descriptive study involved twenty patients who presented to University hospital with resistant chronic plantar heel pain due to plantar fasciitis, were treated with endoscopic plantar fasciotomy. All patients completed a period of at least six months follow up. Data were collected by the modified American Orthopaedic Foot and Ankle Society (AOFAS) Questionnaire, informed consent was applied, and SPSS was used for data entry and analysis.
\end{abstract}

Results: At the end of follow up the mean modified AOFAS of ankle- hind foot score was improved from 49.10 (ranging from 34 to 56) pre-operatively to 90.25 post operatively (ranging from 67 to 100). Seven patients (35\%) had excellent results, ten patients $(50 \%)$ had good results, two patients had fair results, and one patient $(5 \%)$ had a poor result. AOFAS score of pain was improved from a mean of $14.0+9.40$ points pre-operatively (range $0-$ 20 ) to $31.5+6.71$ points post-operatively (range $20-40$ ). AOFAS score of activity of daily living improved from a mean of $4+0$ points pre-operatively to $9.85+0.671$ post-operatively ranging from 7 to 10 points.

Conclusion: Endoscopic release of plantar fascia has positive therapeutic effects in cases of resistant chronic heel pain.

Keywords: endoscopic, release, plantar fascia, resistant chronic heel pain

Importance of Study

Chronic plantar heel pain is one of the most common conditions affecting the foot, by an experimental descriptive study conducted to evaluate the results of endoscopic release of plantar fascia in resistant cases of heel pain, and concluded that endoscopic release of plantar fascia as a positive therapeutic method that is used in cases of resistant chronic heel pain.

\section{Introduction}

Chronic plantar heel pain is one of the most common conditions affecting the foot (Rome, 2005). It can also be said that plantar heel pain is one of the great nuisance pains of the foot and can be a formidable challenge to orthopedic surgeons and other practitioners that manage it. A variety of soft tissue, osseous, and systemic disorders can cause heel pain. By far the most common etiology is plantar fasciitis (Rome, 2005; Ozdemir, Yilmaz, Murat, Karakurt, \& Kursad-Poyraz, 2005; Toomey, 2009). Other less common causes include plantar fascia rupture, fat pad atrophy, fat pad contusion, calcaneal stress fracture, entrapment of the first branch of the lateral plantar nerve, calcaneal apophysitis (Sever's disease), tumor (e.g., osteoid osteoma), tarsal tunnel syndrome, gout, inflammatory arthropathies (e.g., psoriatic arthritis), spondyloarthropathies (e.g., Reiter syndrome), infection, radiculopathy, neuropathy, inappropriate shoe fit and foreign body reaction. (Rome, 2005; Ozdemir et al., 2005; Toomey, 2009; Taunton, Ryan, Clement, McKenzie, Lloyd-Smith, \& Zumbo, 2002; Gill, 1996; Prichasuk \& Subhadrabandhu, 1994; Rano, Fallat, \& Savoy-Moore, 2001; Riddle, Pulisic, Pidcoe, \& 
Johnson, 2003; Kulkarni, 2004)

\subsection{Incidence and Risk Factors}

Chronic plantar heel pain is usually observed in the age between 40 to 60 years old. It is rare under the age of 30 , but has been reported in people from 7 to 85 years (Ozdemir et al., 2005; Toomey, 2009). It is estimated that 1 in 10 people will develop heel pain in their life time (Toomey, 2009). It accounts for about 10 percent of injuries that occur in runners (Ozdemir et al., 2005; Toomey, 2009; Taunton et al., 2002; Gill, 1996; Prichasuk \& Subhadrabandhu, 1994; Rano et al., 2001; Riddle et al., 2003; Kulkarni, 2004) and is common among military personnel (Prichasuk \& Subhadrabandhu, 1994). The predominance of the condition according to sex varies from one study to another (Gill, 1996; Riddle, Pulisic, Pidcoe, \& Johnson, 2003; Furey, 1975). The condition is bilateral in up to a third of cases (Prichasuk \& Subhadrabandhu, 1994; Rano et al., 2001; Riddle et al., 2003; Furey, 1975). Studies have identified risk factors that seem to be associated with plantar fasciitis such as obesity, occupations that require prolonged standing, pes planus (excessive pronation of the foot), limited first metatarsophalangeal joint range of motion, leg length discrepancy, reduced heel pad thickness, reduced calf muscles strength and inferior calcaneal exostoses (Toomey, 2009; Taunton et al., 2002; Gill, 1996; Prichasuk \& Subhadrabandhu, 1994; Rano et al., 2001; Riddle et al., 2003).

There is a slightly higher incidence of heel spurs (75\%) in patients with plantar fasciitis versus asymptomatic patients having about a 63\% incidence of heel spurs (Toomey, 2009). Nonsurgical measures include, but are not limited to, rest, icing, stretching, nonsteroidal anti-inflammatory drugs (NSAIDs), shoe modification, orthoses, physical therapy, weight loss, corticosteroid injection, night splinting, and heel pads (Kulkarni, 2004). In 5-10\% of cases of plantar fasciitis, surgery may be required (Gill, 1996; Furey, 1975; Davis, Severud, \& Baxter, 1974; Miyamoto, Takao, \& Uchio, 2010). It is reserved for those in whom a thorough 6 months of conservative treatment has failed. Plantar fascia release performed by sectioning part of the fascia via an open or endoscopic procedure has been the mainstay of treatment (Kinley, Frascone, Calderone, Wertheimer, Squire, \& Wiseman, 1993; Bader, Park, Gu, \& O'Malley, 2012). Endoscopic plantar fasciotomy is a minimally invasive and minimally traumatic surgical treatment for the common problem of chronic plantar fasciitis (Toomey, 2009; Kinle et al., 1993).

\subsection{Signs and Symptoms}

The pain is on the sole of the foot at the inferior region of the heel. Plantar fasciitis is usually unilateral, but up to 30 percent of cases have a bilateral presentation (Rome, 2005; Aldridge, 2004; Mario \& Roxas, 2005; Buchbinder, 2004). Risk factors for plantar fasciitis are such as obesity, occupations that require prolonged standing, pes planus (excessive pronation of the foot), limited first metatarsophalangeal joint range of motion, length discrepancy, reduced heel pad thickness, reduced calf strength and inferior calcaneal exostoses (Toomey, 2009; Taunton et al., 2002; Gill, 1996; Prichasuk \& Subhadrabandhu, 1994; Rano et al., 2001; Riddle et al., 2003). Plain radiographs may reveal a plantar heel spur, which delineates the presence of abnormal stresses across the plantar fascia for at least 6 months (Gill, 1996). The heel spur is not the cause of the symptoms but, rather, a sequelae of the process. Studies have revealed that $50 \%$ of symptomatic patients and $20 \%$ of asymptomatic patients have heel spurring. Bone scans and magnetic resonance imaging (MRI) may also serve useful, but are not routinely used. MRI can show thickening and edema of the plantar fascia (Toomey, 2009; Buchbinder, 2004; Young, 2001; DiMarcangelo \& Yu, 1997).

\subsection{Diagotic and Treatment Options}

Plantar fasciitis is considered a self-limiting condition (DiMarcangelo \& Yu, 1997; Cole, Seto, Gazewood, Charles, \& John, 1995; Barrett, Day, \& Pignetti, 1995; Blanco, Leon, \& Guthrie, 2001; Hake, 2000; El-Shazly, El-Hilaly, Abou El-Soud, \& El-Sayed, 2010; Komatsu, Takao, \& Innami, 2011; Othman \& Ragab, 2010). Of the many treatment options available for plantar fasciitis; one of the most effective and also the most fundamental is rest and avoidance of aggravating activity provides significant relief. One study cited rest as the treatment that worked best for 25 percent of plantar fasciitis patients (Kulkarni, 2004). Fortunately, 85-90 percent of these cases will respond to conservative treatment, and 15-10 percent will need operative intervention (Davis et al., 1994; Baxter \& Pfeffer, 1992). Surgery for plantar fasciitis should be considered only after all other forms of treatment have failed (DuVries, 1957). Hassab and El-Sherif suggested drilling of the calcaneus to relief heel pain. They performed 68 operations in 60 patients and reported excellent results in 62, good in 2, and poor in 4 (Hassab \& El-Sherif, 1974).

Santini et al treated 25 feet in 21 patients with drilling of the calcaneus, and the indication was chronic heel pain in combination with increased uptake in the bone scan. Three holes were drilled in the medial cortex of the calcaneus. Six of seven patients who had another bone scan post operatively showed resolution of the increased uptake. The outcome was worse in patients with rheumatoid disease and Haglund deformity (Santini, Rebeccato, Schiavon, \& Nogarin, 2003). One of the most commonly overlooked causes of chronic heel pain is entrapment 
of the first branch of the lateral plantar nerve (Kenzora, 1987; Baxter \& Pfeffer, 1992; Baxter \& Thigpen, 1984). Entrapment of the nerve accounts for about 20 percent of chronic heel pain. Entrapment occurs as the nerve changes from a vertical to horizontal direction around the medial plantar aspect of the heel. The exact site of compression is between the heavy deep fascia of the abductor halluces muscle and the medial caudal margin of the medial head of the quadratus plantae muscle. Entrapment of the first branch of the lateral plantar nerve is more common in athletes who are on their toes for a significant amount of time (e.g., sprinters, ballet dancers) by well-developed abductor hallucis. Another potential site of entrapment of the first branch is the point at which the nerve passes just distal to the medial calcaneal tuberosity (Kenzora, 1987; Andreasen Struijk, Birn, Teglbjaerg, Haase, \& Struijk, 2010).

Inflammation and spur formation in the origin of the flexor brevis muscle can produce sufficient swelling to cause compression of the nerve against the plantar fascia (Kenzora, 1987; Andreasen Struijk et al., 2010). Diagnosis of entrapment of the first branch of the lateral plantar nerve is based on clinical findings. Patients usually report pain radiating distally and proximally from the medial aspect of the heel, and they may report paraesthesia. Pain may radiate proximally into the calf along the course of the nerve (Valleix phenomenon). A positive Tinel sign (percussion of the irritated nerve, causing tingling or numbness radiating in the nerve's distribution) may be present. Atrophy of the abductor qunti may be present, but it is difficult to detect. The point of maximal tenderness is located on the medial heel. Dorsiflexion and eversion of the ankle may exacerbate symptoms (Mario \& Roxas, 2005; Cole et al., 1995; Labib, Gould, Rodriguez-del-Rio, \& Lyman, 2002; Resnick, Hudgins, Buschmann, Kummer, \& Jahss, 1999; Dailey, 1991).

Imaging studies are not indicated unless a space-occupying lesion is suspected, in which case MRI should be obtained. Electromyography and nerve conduction velocity studies are not consistent (DiMarcangelo \& Yu, 1997; Komatsu, Takao, \& Innami, 2011; Cheung \& Zhang, 2006; Parrett, 2002; Tweed, Barnes, Allen, \& Campbell, 2009). Baxter described operative decompression of the first branch of the lateral plantar nerve in 20patient with 34 heels; 82 percent of patients had complete relief (Baxter \& Pfeffer, 1992; Baxter \& Thigpen, 1984).

Surgery for releasing plantar fascia may be divided into 3 procedures: (1) Percutaneous release, (2) open surgery with plantar medial incision, and (3) endoscopic surgery. Percutaneous release is a less invasive surgery but is not a reliable method to release the plantar fascia with inferior results compared with the two other procedure (Komatsu, Takao, \& Innami, 2011). The most common procedure is a partial plantar fasciotomy that may be either open or closed. Partial release of less than $40 \%$ of the fascia is recommended to minimize the effect on arch instability and maintain normal foot biomechanics (Cheung \& Zhang, 2006). Total plantar fasciotomy, may lead to loss of stability of the medial longitudinal arch and abnormalities in gait, in particular an excessively pronated foot (Tweed, Barnes, Allen, \& Campbell, 2009).

In 1957, DuVries described the classic surgery for plantar fasciitis or heel spur syndrome. He performed the surgery through a medial incision in which he removed the fascia from its insertion and subsequently removed the heel spur (DuVries, 1957). Others have used a minimal incision technique with just a stab incision on the plantar or medial aspect of the foot (Parrett, 2002).

After cadaveric investigation, researchers performed the first series of endoscopic plantar fasciotomies, which was described and recommended by Barrett and Day in 1991 (Hake, 2000; Barrett \& Day, 1991). The two-portal procedure allowed for better visualization of the anatomical structures. It also had a smaller diameter incision and dissection, so it was less traumatic than the one-portal system. Most importantly, far more surgeons have been able to achieve successful results in using the two-portal approach (Barrett \& Day, 1991).

Kinley et al, compared the endoscopic procedure (66 cases) with traditional surgery (26 cases) demonstrating an $80 \%$ resolution of symptoms, 4 weeks sooner than with traditional treatment, as well as less postoperative pain and fewer complications. Endoscopic plantar fasciotomy offered several important advantages; including minimal soft tissue dissection, excellent visualization of the plantar fascia, precision in transecting only the medial one third of the plantar fascia, minimal; postoperative pain with early return to full weight bearing status, and earlier return to activities and work (Kinley et al., 1993).

In Brekke and Green's comparison of surgical procedures for releasing the plantar fascia (54 patients), the 17 endoscopic plantar fasciotomy patients had the least postoperative pain and returned to normal activities 5 weeks earlier than those underwent minimal incision or open approach procedures (Brekke \& Green, 1998).

Endoscopic plantar fasciotomy can be successful even when shock wave therapy has failed. El-Shazly performed endoscopic plantar fascia release after failed shock wave therapy in 18 patients with exclusion of rheumatoid arthritis, peripheral neuropathy, pes planus, and gout. Of the patients of this study, $9(50 \%)$ had excellent results, $6(35 \%)$ had good results, two patients $(10 \%)$ had fair results, and one patient $(5 \%)$ had failure of improvement of pain (El-Shazly et al., 2010). 


\subsection{Aim}

The aim of this study is to evaluate the results of endoscopic release of plantar fascia in resistant cases of heel pain.

\section{Patients}

Between April 2011 and May 2013, twenty patients presented to **** University hospital with resistant chronic plantar heel pain due to plantar fasciitis, were treated with endoscopic plantar fasciotomy. All patients completed a period of at least six months follow up.

\section{The inclusion criteria were}

- Insidious onset of heel pain with the first steps out of bed or after periods of rest. The pain tends to get better with increased activity after the foot loosens up.

- Upon physical examination, the most tender point is that elicited upon palpation of the plantar-medial calcaneal tubercle at the site of plantar fascial insertion to the heel bone.

- Normal radiography of the foot with or without calcaneal spur.

- Symptoms for at least a year.

- At least one year of conservative therapy without improvement.

\section{The exclusion criteria were}

Those suggested to have: plantar fascia rupture, fat pad atrophy, fat pad contusion, calcaneal stress fracture, tumor (e.g., osteoid osteoma), gout, Inflammatory arthropathies (e.g., psoriatic arthritis), spondyloarthropathies (e.g., Reiter syndrome), infection, tarsal tunnel syndrome, radiculopathy, neuropathy, inappropriate shoe fit and foreign body reaction.

\section{Age}

The youngest patient was 26 years and the oldest was 64 with mean age of 44.15 years (Table 1).

Table 1. Distribution of the patients according to the age

\begin{tabular}{lll}
\hline & Frequency & Percent \\
\hline $20-29$ & 1 & 5.0 \\
$30-39$ & 5 & 25.0 \\
$40-49$ & 7 & 35.0 \\
$50-59$ & 6 & 30.0 \\
$60<$ & 1 & 5.0 \\
Total & 20 & 100.0 \\
Mean & 44.15 & \\
Std. Deviation & 10.179 & \\
\hline
\end{tabular}

\section{Side affected}

Right side was involved in 9 patients (45\%) and left side 11 patients (55\%).

\section{Occupation}

Five patients were manual workers $(25 \%)$, six patients were office workers $(30 \%)$ and nine patients were housewives $(45 \%)$ (Table 2$)$. 
Table 2. Distribution of the patients according to the occupation

\begin{tabular}{lll}
\hline & Frequency & Percent \\
\hline Housewives & 9 & 45.0 \\
Manual worker & 5 & 25.0 \\
Office worker & 6 & 30.0 \\
Total & 20 & 100.0 \\
\hline
\end{tabular}

\section{Duration of symptoms}

Of the 20 patients, there were three patients suffering from symptoms for about 12 months, five for about 18 months, five patients for about 24 months, and seven patients for more than 24 months. The range of duration was 12-48 months and the mean value was 26.10 months (Table 3 ).

Table 3. Duration of symptoms

\begin{tabular}{lll}
\hline Months & Frequency & Percent \\
\hline 12. & 3 & 15.0 \\
18. & 5 & 25.0 \\
24. & 5 & 25.0 \\
$24<$ & 7 & 35.0 \\
Total & 20 & 100.0 \\
Mean & 26.10 & \\
Std. Deviation & 11.23 & \\
\hline
\end{tabular}

\section{Associated medical conditions}

Of the twenty patients four patients $(20 \%)$ had diabetes mellitus, and two associated Haglund deformity (10\%). (Table 4).

Table 4. Associated medical conditions

\begin{tabular}{lll}
\hline & Frequency & Percent \\
\hline DM & 4 & 20.0 \\
Haglund deformity & 2 & 10.0 \\
None & 14 & 70.0 \\
Total & 20 & 100.0 \\
\hline
\end{tabular}

\section{Previous treatment}

All the included patients in the study had previous unsuccessful treatment in the form of non- steroidal antiinflammatory drugs for at least 12 months, and all of them had corticosteroid injection at least once. In addition to the medical treatment 6 patients received physiotherapy (30\%) and 1 patient had extracorporeal shock-wave therapy (ESWT) $(5 \%)$ as shown in (Table 5).

Table 5. Type of previous treatment

\begin{tabular}{lll}
\hline & Frequency & Percent \\
\hline Medication only & 13 & $\mathbf{6 5 \%}$ \\
Medication \& Physiotherapy & 6 & $\mathbf{3 0 \%}$ \\
Medication and extracorporeal shock-wave therapy (ESWT) & 1 & $\mathbf{5 \%}$ \\
Total & $\mathbf{2 0}$ & $\mathbf{1 0 0 \%}$ \\
\hline
\end{tabular}




\section{Methods}

\subsection{Methods of Initial Examination and Management}

All patients were examined both clinically and radiologically on admission to the hospital as follows:

1) General assessment of the patient.

2) Local assessment of the heel.

3) Laboratory investigations (CBC, ESR, CRP, serum uric acid, latex test for rheumatoid arthritis).

4) Plain $X$ ray of ankle and heel (antro-posterior and lateral views).

\subsection{Methods of Treatment}

\section{1) Patient preparation}

-Prophylactic antibiotics

\section{2) Patient position}

3) The patient was placed supine, with the affected heel hanging off the end of the surgical table. (Figure 1)

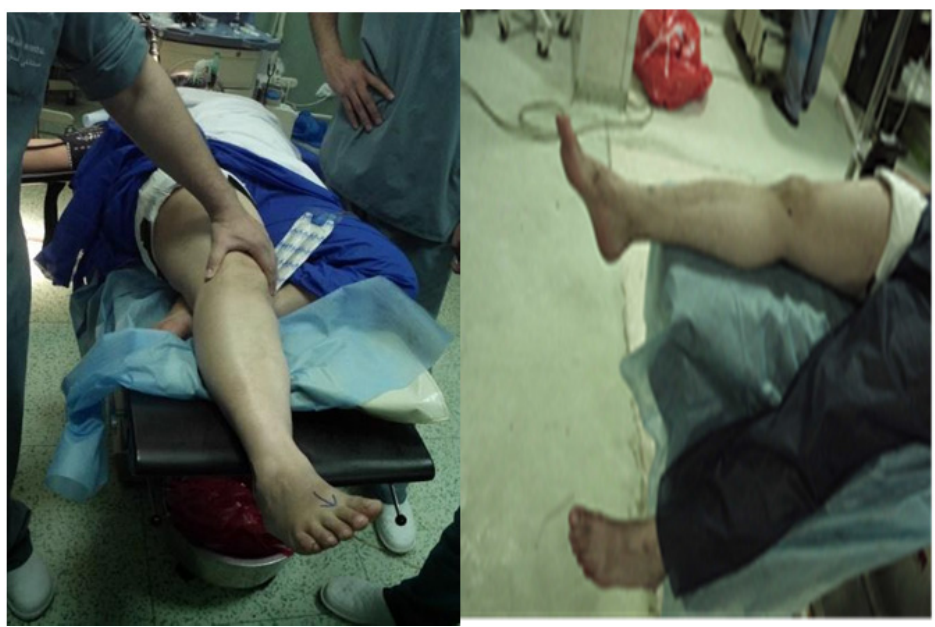

Figure 1. Patient position

4) Tourniquet: On the thigh.

5) Approach: Two portals technique (medial and lateral).

6) Techniques:

- The medial portal was located over a reference point that was immediately anterior and inferior to the inferior aspect of the medial calcaneal tubercles viewed on lateral projection. (Figure 2).

- A 5-mm stab incision was performed, incising the skin only, then bluntly dissecting superior to the level of the plantar fascia.

- Care was taken to ensure that the dissection was superior to the fascia to avoid neurovascular injury.

- Arthroscopic trocar sheath was then introduced into this channel and advanced across the superior surface of the plantar fascia to the lateral aspect of the foot.

- A 5-mm incision was made over the trocar's tip, allowing the sheath to be passed through the skin, and then the trocar was removed, leaving the sheath in place. 


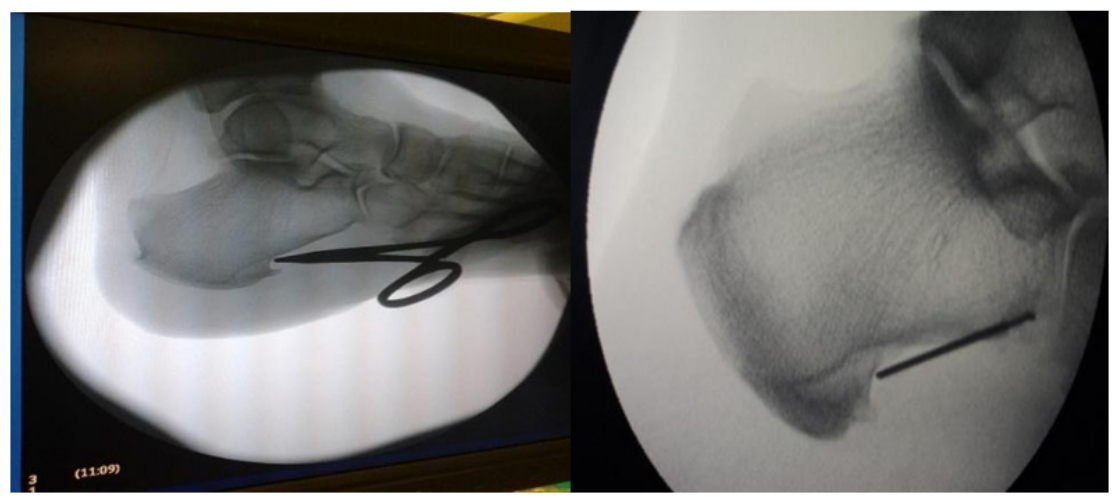

Figure 2. The medial portal on lateral projection

- The endoscope was then introduced medially and the fascial probe laterally.

- Using the endoscope, the entire superior surface of the plantar fascia was viewed on the monitor (Figure $3 \mathrm{~A})$.

- The endoscope was then introduced laterally and the arthroscopic ablation device was introduced medially to sever the medial one third of the fascia (Figure 3B).

- Care was taken to perform only a medial one-third release to minimize the amount of destabilization of the longitudinal arch.

- As the fascia was severed, the muscle of the flexor digitorum brevis was visualized.

- The calcaneal spur was resected in all cases using an arthroscopic burr until the original fascial origin was clearly seen (Figure 3C).

- The ankle and toes were maximally dorsiflexed and separation of the edges of the plantar fascia was seen, and the fat pad was visualized beneath the fascia to ensure complete removal (Figure 3D).

\section{7) After treatment:}

Patients were allowed protected weight bearing wearing heel cushion immediately after surgery as tolerated, but without excessive ambulation. The patient could return to regular shoes fitted with an orthotic appliance as soon as tolerated. 


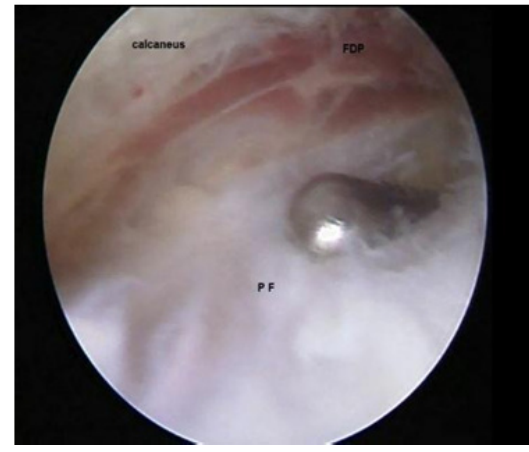

A

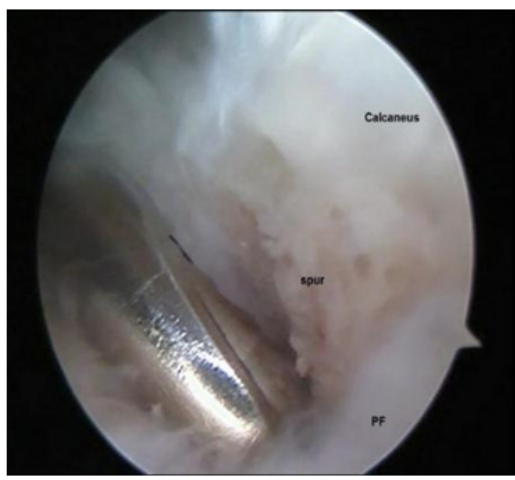

$\mathrm{C}$

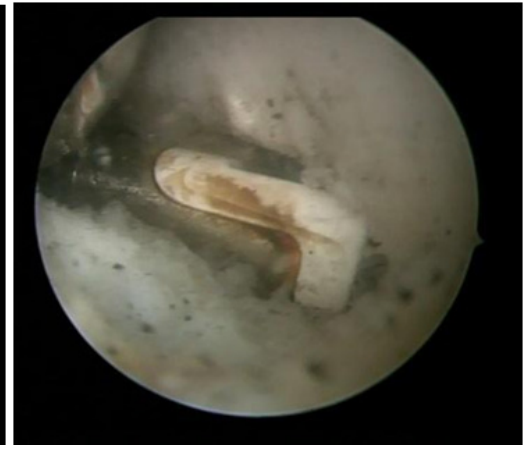

$\mathrm{B}$

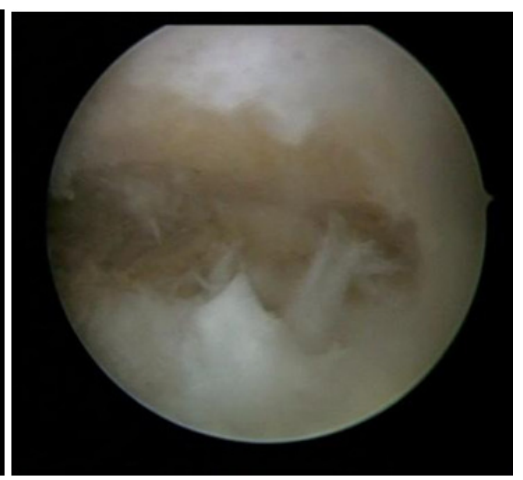

D

Figure 4. (A) Endoscopic view of calcaneus and plantar fascia. (FDB: flexor digitorum brevis, PF: plantar fascia.) (B) The medial half of the plantar fascia was resected with the arthroscopic ablation device. (C) A heel spur was resected with an arthroscopic burr. (D) The fat pad was visualized beneath the fascia to ensure complete removal

\section{I) Methods for evaluation the results:}

The results of treatment were assessed as regards the modified American Orthopaedic Foot and Ankle Society (AOFAS) ankle- hind foot score (Table 6). The patients were all followed up every two weeks for the first three months post-operative and then monthly for the following three months. All the patients completed the 6 months follow up period.

Table 6. Modified American Orthopaedic Foot and Ankle Society (AOFAS) ankle- hind foot score

\begin{tabular}{ll}
\hline Pain & 40 \\
\hline None & 30 \\
Mild, occasional & 20 \\
Moderate, daily & 0 \\
Severe, almost always present & \\
FUNCTION & 10 \\
Activity limitation, support requirement & 7 \\
No limitation, no support & 4 \\
No limitation, no support, limitation of recreational activities & 0 \\
limitation of daily and recreational activities & \\
Severe limitation of daily and recreational activities, crutches, wheel chair & \\
\hline
\end{tabular}


Maximum walking distance
Greater than 1000 meters
$500-1000$ meters
$100-400$ meters
Less than 100 meters

Walking surfaces

$\begin{array}{ll}\text { No difficulty on any surfaces } & 5\end{array}$

Some difficulty on uneven terrain, stairs, inclines ladders 3

Severe difficulty on uneven terrain, stairs, inclines ladders $\quad 0$

Gait abnormalities

$\begin{array}{lr}\text { None, slight } & 8\end{array}$

$\begin{array}{lr}\text { Obvious } & 4\end{array}$

$\begin{array}{lr}\text { Marked } & 0\end{array}$

Sagittal motion (flexion, extension)

Normal

$\begin{array}{ll}\text { Restriction } 15^{\circ}-29^{\circ} & 4\end{array}$

Restriction less than $\mathbf{1 5}^{\circ} \quad 0$

Hind foot motion( inversion, eversion)

$\begin{array}{ll}\text { Normal } & 5\end{array}$

Moderate Restriction (25\%- 74\% normal) 3

Marked restriction (less than $\mathbf{2 5 \%}$ normal) 0

\begin{tabular}{lc} 
Ankle-hind foot stability (anteroposterior, varus-valgus) & 6 \\
Stable & 0 \\
\hline Unstable & 15 \\
\hline Patient satisfaction & 8 \\
Good & 0 \\
Poir & 100 \\
Total score & 0
\end{tabular}

A total score of 90 points or higher was considered excellent, 80-89 points good, 70-79 points fair and a score lower than 70 was considered poor.

\section{Methods of statistical analysis:}

Statistical analysis of the data was done using SPSS- $20^{\circledR}$ program (Statistical Package for Social Science version 20.0).

\section{Results}

At the end of the follow up period, the modified American Orthopedic Foot and Ankle Society (AOFAS) anklehind foot mean score was 90.25 points ranging from 67 to $100 \pm 8.60$ points. Preoperatively, the mean score was 49.10 points ranging from 34 to $56 \pm 9.53$ points (Tables $7 \& 8)$. Seven patients $(35 \%)$ had excellent results, ten patients $(50 \%)$ had good results, two patients had fair results $(10 \%)$, and one patient $(5 \%)$ had poor result. (Tables $7 \& 8$ ). 
Table 7. Post-operative total score

\begin{tabular}{lll}
\hline & $\begin{array}{l}\text { Modified American Orthopaedic Foot and Ankle } \\
\text { Society (AOFAS) ankle- hind foot scale (\%) }\end{array}$ & Number of patients \\
\hline Excellent (90-100 points) & $35 \%$ & 7 \\
Good (80-89 points) & $50 \%$ & 10 \\
Fair (70-79 points) & $10 \%$ & 2 \\
Poor (<70 points) & $5 \%$ & 1 \\
Total & $100 \%$ & 20 \\
\hline
\end{tabular}

The difference between the means of pre-operative and 6 months postoperative total score was statistically significant $(\mathrm{p}<0.0001)$.

Table 8. Pre \& post-operative score

\begin{tabular}{lll}
\hline & Pre & Post 6 m \\
\hline Score & & \\
Min. - Max. & $34.0-56.0$ & $67.0-100.0$ \\
Mean \pm SD & $49.10 \pm 9.53$ & $90.25 \pm 8.60$ \\
P & & $<0.001^{*}$ \\
\hline
\end{tabular}

p: Stands for adjusted Bonferroni p-value for ANOVA with repeated measures for comparison between pre with each other period;

*: Statistically significant at $\mathrm{p} \leq 0.05$.

Pain:

At the end of the follow up period, the mean final modified American Orthopaedic Foot and Ankle Society (AOFAS) ankle- hind foot scale for pain was $31.50 \pm 6.71$ points ranging from 20 to 40 points. Preoperatively, the mean score was $14.00 \pm 9.40$ points ranging from 0 to 20 points. The difference was statistically significant $(\mathrm{p}<0.0001)$ (Table 9).

Table 9. Comparison between pre and post-operative pain score

\begin{tabular}{llll}
\hline & Preoperative & Postoperative & P \\
\hline Mean & 14.00 & 31.50 & $<0.0001$ \\
Std. Deviation & 9.40 & 6.71 & \\
Min & 0 & 20 & \\
Max & 20 & 40 & \\
Range & 20 & 20 & \\
\hline
\end{tabular}

Statistically significant at $\mathrm{p} \leq 0.05$.

\section{Function and activity limitation:}

At the end of the follow up period, the mean modified American Orthopaedic Foot and Ankle Society (AOFAS) ankle- hind foot score for activity of daily living was $9.85 \pm 0.671$ points ranging from 7 to 10 points. Preoperatively, the mean score was $4 \pm 0$ points. The difference was statistically significant $(t=-14.95$ and $\mathrm{p}<0.0001$ ) (Table 10). 
Table 10. Comparison between pre and postoperative score of Function

\begin{tabular}{llll}
\hline & Preoperative & Postoperative & P \\
\hline Mean & 4 & 9.85 & $<0.0001$ \\
Std. Deviation & 0 & 0,671 & \\
Min & 4 & 7 & \\
Max & 4 & 10 & \\
Range & 0 & 3 & \\
\hline
\end{tabular}

Statistically significant at $\mathrm{p} \leq 0.05$

\section{Maximum walking distance:}

At the end of the follow up period, the mean modified American Orthopaedic Foot and Ankle Society (AOFAS) ankle- hind foot score for maximum walking distance was $4.40 \pm 0.94$ points ranging from 2 to 5 points. Preoperatively, the mean score was $3.10 \pm 1.02$ points ranging from 2 to 4 points. The difference was statistically significant $(\mathrm{p}<0.0001)$ (Table 11).

Table 11. Comparison between pre and post-operative score of maximum walking distance

\begin{tabular}{llll}
\hline & Preoperative & Postoperative & P \\
\hline Mean & 3.10 & 4.40 & $<0.0001$ \\
Median & 2 & 5 & 0.94 \\
Std. Deviation & 1.02 & 2 & 5 \\
Min & 2 & 3 & \\
Rax & 4 & & \\
\hline
\end{tabular}

Statistically significant at $\mathrm{p} \leq 0.05$

\section{Patient satisfaction:}

At the end of the follow up period, the mean score for patient satisfaction was $14.25 \pm 3.35$ ranging from 0 to 15 . Preoperatively, the mean score was $0.0 \pm 0.0$. The difference was statistically significant $(\mathrm{p}<0.0001)($ Table 12$)$.

Table 12. Comparison between pre and post -operative score of patient satisfaction

\begin{tabular}{llll}
\hline & Preoperative & Postoperative & P \\
\hline Mean & 0 & 14.25 & $<0.0001$ \\
Median & 0 & 15.00 & \\
Std. Deviation & 0 & 3.35 & 0 \\
Min & 0 & 15 & 15 \\
Max & 0 & 0 & \\
Range & 0 & & \\
\hline
\end{tabular}

\section{Return to work:}

At the end of the follow up period, the mean period passed for patients to return to work was $2.0 \pm 0.32$ months ranging from 1 to 3 months. (Table 13) 
Table 13. Duration of return to work

\begin{tabular}{lll}
\hline Return to work & No & percent \\
\hline $\mathbf{1}$ month & 1 & $5 \%$ \\
$\mathbf{2}$ months & 18 & $80 \%$ \\
$\mathbf{3}$ months & 1 & $5 \%$ \\
\hline
\end{tabular}

There were no differences between pre and post-operative mean score of difficulty of walking on uneven surfaces, gait abnormalities, sagittal ankle motion (flexion, extension), hind foot motion (inversion, aversion) or Ankle-hind foot stability (anteroposterior, varus-valgus).

\section{Factors that may affect the final outcome:}

There was no statistically significant relationship between age, gender, right and left side, duration of the complaint, associated medical conditions (diabetes or Haglud deformity), the type of previous received treatment, occupation of the patients and the final score Tables (14-20).

Table 14. Relation between final score with age

\begin{tabular}{llllll}
\hline \multirow{2}{*}{ Age } & \multicolumn{2}{l}{ Final score } & & & Excellent \\
\cline { 2 - 5 } & Poor & Fair & $50-51$ & $26.0-64.0$ & $30.0-50.0$ \\
\hline Min. - Max. & $55.0-55.0$ & $50.50+0.71$ & $44.30 \pm 13.26$ & $42.00 \pm 4.97$ & 0.346 \\
Mean \pm SD & $55.0 \pm-$ & 50.50 & 41.00 & 40.0 & \\
Median & 55.0 & & &
\end{tabular}

Table 15. Relation between final score and sex

\begin{tabular}{|c|c|c|c|c|c|c|c|c|c|c|c|}
\hline \multirow[t]{3}{*}{ Gender } & \multicolumn{8}{|c|}{ Final score } & \multirow[t]{3}{*}{ Total } & \multirow[t]{3}{*}{ Mean } & \multirow[t]{3}{*}{$\mathbf{P}$} \\
\hline & \multicolumn{2}{|c|}{ Poor } & \multicolumn{2}{|c|}{ Fair } & \multicolumn{2}{|c|}{ Good } & \multicolumn{2}{|c|}{ Excellent } & & & \\
\hline & No. & $\%$ & No. & $\%$ & No. & $\%$ & No. & $\%$ & & & \\
\hline Male & 0 & 0.0 & 1 & $\begin{array}{l}50 . \\
0\end{array}$ & 2 & $\begin{array}{l}20 . \\
0\end{array}$ & 5 & 71.00 & 8 & 93.50 & 1.0 \\
\hline Female & 1 & $\begin{array}{l}100 . \\
0\end{array}$ & 1 & $\begin{array}{l}50 . \\
0\end{array}$ & 8 & $\begin{array}{l}80 . \\
0\end{array}$ & 2 & 29.00 & 12 & 88.08 & \\
\hline
\end{tabular}

Table 16. Relation between final score and side affected

\begin{tabular}{llllllll}
\hline & Number & Mean & Median & SD & Min & Max & Range \\
\hline Right & 9 & 88.0 & 90.00 & 10.39 & 67 & 100 & 33 \\
Left & 11 & 92.09 & 89.00 & 6.77 & 79 & 100 & 21 \\
P & 0.707 & & & & & & \\
\hline
\end{tabular}

Table 17. Relation between final score with the duration of the symptoms

\begin{tabular}{llllll}
\hline \multirow{2}{*}{ Duration of c/o (month) } & \multicolumn{2}{l}{ Final score } & & & Excellent \\
\cline { 2 - 5 } & Poor & Fair & Good & $12.0-48.0$ & $12.0-36.0$ \\
\hline Min. - Max. & $36.0-36.0$ & $36.0-48$ & $24.60 \pm 11.82$ & $22.29 \pm 7.51$ & $\mathbf{0 . 0 5 1}$ \\
Mean \pm SD & $36.0 \pm-$ & $42.0+8.45$ & 21.0 & 24.0 & \\
Median & 36.0 & 42.0 & & \\
\hline
\end{tabular}

$\mathrm{p}$ : $\mathrm{p}$ value for $\mathrm{F}$ test (ANOVA) for comparing between final score categories. 
Table 18. Relation between final score with associated medical conditions

\begin{tabular}{llllllll}
\hline & Number & Mean & Median & SD & Min & Max & Range \\
\hline NO Associated condition & 14 & 93.60 & 90.00 & 5.29 & 89 & 100 & 11 \\
Diabetes & 4 & 81.67 & 89.00 & 12.70 & 67 & 89 & 22 \\
Haglund deformity & 2 & 78.00 & 78.00 & 1.41 & 77 & 79 & 2 \\
P & 0.064 & & & & & & \\
\hline
\end{tabular}

Table 19. Relation between final score with previous treatment

\begin{tabular}{|c|c|c|c|c|c|c|c|c|c|}
\hline \multirow{3}{*}{ Previous treatment } & \multicolumn{8}{|c|}{ Final score } & \multirow{3}{*}{$\mathbf{p}$} \\
\hline & \multicolumn{2}{|c|}{ Poor } & \multicolumn{2}{|l|}{ Fair } & \multicolumn{2}{|c|}{ Good } & \multicolumn{2}{|c|}{ Excellent } & \\
\hline & No. & $\%$ & No. & $\%$ & No. & $\%$ & No. & $\%$ & \\
\hline Medication only & 1 & 100.0 & 1 & 50.0 . & 7 & 70.0 & 4 & 57.1 & \\
\hline Physiotherapy & 0 & 0.0 & 0 & 0.0 & 3 & 30.0 & 3 & 42.9 & 0.159 \\
\hline $\begin{array}{l}\text { Extracorporeal shock-wave therapy } \\
\text { (ESWT) }\end{array}$ & 0 & 0.0 & 1 & 50.0 & 0 & 0.0 & 0 & 0.0 & \\
\hline
\end{tabular}

Table 20. Relation between final score with occupation

\begin{tabular}{|c|c|c|c|c|c|c|c|c|c|}
\hline \multirow{3}{*}{ Occupation } & \multicolumn{8}{|c|}{ Final score } & \multirow{3}{*}{ p } \\
\hline & \multicolumn{2}{|c|}{ Poor } & \multicolumn{2}{|c|}{ Fair } & \multicolumn{2}{|c|}{ Good } & \multicolumn{2}{|c|}{ Excellent } & \\
\hline & No. & $\%$ & No. & $\%$ & No. & $\%$ & No. & $\%$ & \\
\hline Office worker & 1 & 100.0 & 0 & 0.0 & 2 & 20.0 & 3 & 42.9 & \\
\hline Manual work & 0 & 0.0 & 1 & 50.0 & 1 & 10.0 & 3 & 42.9 & 0.768 \\
\hline Housewives & 0 & 0.0 & 1 & 50.0 & 7 & 70.0 & 1 & 14.2 & \\
\hline
\end{tabular}

$\mathrm{p}$ : $\mathrm{p}$ value for Monte Carlo test for comparing between final score categories

\section{Discussion}

This study evaluates the results of endoscopic plantar fascial release through two portals. At the end of follow up the mean modified American Orthopaedic Foot and Ankle Society (AOFAS) ankle- hind foot score improved from 49.10 (ranging from 34 to 56) pre-operatively to 90.25 post operatively (ranging from 67 to 100). Seven patients $(35 \%)$ had excellent results, ten patients $(50 \%)$ had good results, two patients had fair results, and one patient $(5 \%)$ had poor result. These results were comparable to the results of other studies.

Barrett and Day's described a 100\% success rate with seven endoscopic plantar fasciotomy procedures (Barrett $\&$ Day, 1991). After two years, they followed up with a review of 65 procedures reporting $95.3 \%$ total relief of symptoms (Barrett \& Day, 1993). Kinley et al compared the endoscopic procedure (66 cases) with traditional open surgery (26 cases) demonstrating an $80 \%$ resolution of symptoms with endoscopic plantar fasciotomy 4 weeks sooner than with traditional treatment, as well as less postoperative pain and fewer complications (Kinley et al., 1993).

O'Malley et al. reported 23 feet on 20 patients treated with endoscopic plantar fascia release. The mean American Orthopaedic Foot and Ankle Society (AOFAS) ankle- hind foot score improved from 62 points to 80 points (Bazaz \& Ferkel, 2007). Harry Burke reported an 83\% success rate (with 2-year follow-up) with 265 endoscopic plantar fasciotomy patients over a 6-year period (Hake, 2000).

Hake performed 40 endoscopic plantar fasciotomy procedures, 36 have resulted in the resolution of heel pain, two cases were unchanged from the previous pain level, and the two remaining patients related less pain than preoperatively but were not pain free (Hake, 2000).

Rodriguez Blanco et al. operated 38 feet in 30 patients. At 1-year follow-up, 34 feet were available for evaluation. They reported excellent results in 29 patients, and good results in 5 patients. These five patients had transient symptoms that resolved with a cycle of 7 to 10 physical therapy sessions without further recurrence despite return to full activity (Blanco et al., 2001). 
Bazaz and Ferkel reported that the mean American Orthopaedic Foot and Ankle Society (AOFAS) ankle-hind foot score improved from 66 points to 88 points. The difference in the final score was because in our study we used modified American Orthopaedic Foot and Ankle Society (AOFAS) ankle- hind foot score (Bazaz \& Ferkel, 2007).

Urovitz et al. studied the use of endoscopic plantar fasciotomy in the treatment of chronic heel pain that was irresponsive to conservative treatment in 55 patients. The mean follow-up was 18 months. The mean preoperative American Orthopaedic Foot and Ankle Society (AOFAS) ankle-hind foot score was 66.5 points, and improved to 88.2 points postoperatively (E. Urovitz \& A. Urovitz, 2008).

El-Shazly et al. have studied endoscopic plantar fascia release after failed extracorporeal shock wave therapy (ESWT) in eighteen patients complained of persistent painful heel after treatment by ESWT for at least 6 months. After 2 years of follow-up Nine patients $(50 \%)$ had excellent results, six $(35 \%)$ had good results, one (10\%) had a fair result, and one (5\%) had failure of improvement of pain (El-Shazly et al., 2010).

Komatsu et al. reported $100 \%$ success rate of endoscopic plantar fasciotomy that was performed in 10 feet in 8 patients who were treated conservatively for more than 6 months with failure to relieve their symptoms. The mean American Orthopaedic Foot and Ankle Society (AOFAS) ankle-hind foot was 64.2 \pm 6.3 points before surgery and 92.6 \pm 7.1 points at 2 years after surgery (Komatsu, Takao, \& Innami, 2011). Radwan et al. also compared endoscopic plantar fasciotomy versus extracorporeal shock wave in 65 patients. They found "Excellent" or "Good" results obtained in 70.6\% of extracorporeal shock wave group and $77.4 \%$ of endoscopic plantar fasciotomy group (Radwan, Mansour, \& Badawy, 2012). In the study of Bader et al about the functional outcome of endoscopic plantar fasciotomy 48 patients ( 56 feet) underwent endoscopic plantar fasciotomy. The mean postoperative American Orthopaedic Foot and Ankle Society (AOFAS) ankle-hind foot score improved from 54 to 93 points (DiMarcangelo \& Yu, 1997).

In a retrospective study by Nery et al twenty-three patients underwent endoscopic plantar fascia release for symptomatic plantar fasciopathy unresponsive to non-operative measures. American Orthopaedic Foot \& Ankle Society (AOFAS) ankle- hind foot score improved from 55 (41-63) points pre-operatively to 89 (41-97) points post-operatively (Parrett, 2002).

\section{Post Operation Progress}

In our study pain gradually improved post-operatively; patients could step on toes the first day after the procedure and patients could wear ordinary shoes after two weeks and step with whole sole while wearing orthotic cushions but with affordable pain that needed the use of analgesics. Patients could return to work and to full activity in about 6 weeks. The modified American Orthopaedic Foot and Ankle Society (AOFAS) anklehind foot score for pain improved from a mean of $14.0 \pm 9.40$ points pre-operatively (range $0-20$ ) to $31.5 \pm 6.71$ points post-operatively (range $20-40$ ). Two patients with Haglund deformity reported moderate posterior heel pain postoperatively, three patients had mild tolerable lateral pain that did not affect their daily activities, and one patient had moderate heel pain after subsidence of wound infection.

Blanco et al operated on 38 feet. They reported excellent results with pain 0-2 points on visual analog score in 29 patients, and good results with 3-4 points on visual analog score in 5 patients, these five patients had transient symptoms that resolved with a cycle of 7 to 10 physical therapy sessions without further recurrence despite return to full activity (Blanco et al., 2001).

Urovitz et al studied the use of endoscopic plantar fasciotomy in the treatment of chronic heel pain that was unresponsive to conservative treatment. The mean preoperative American Orthopaedic Foot and Ankle Society (AOFAS) ankle-hind foot pain score was 18.6 points; the mean postoperative pain score was 31.1 points (E. Urovitz \& A. Urovitz, 2008).

Othman and Ragab compared endoscopic plantar fasciotomy versus extracorporeal shock wave therapy for treatment of chronic plantar fasciitis. In the first group treated with endoscopic plantar fasciotomy, pain improved from 9.1 to 1.6 points using visual analog score. In the second group treated with extracorporeal shock wave therapy pain improved from 9 to 2.1 using visual analog score (Othman \& Ragab, 2011).

EL -Shazly et al reported improvement of the morning pain score from a mean $79.76 \pm 6.5$ preoperatively to a mean of $5.88 \pm 9.7$ postoperatively. According to their grading of the results regarding morning pain after 2 years follow-up, 15 patients (17 feet) had an excellent score (85\%), 1 patient (2 feet) had a fair score $(10 \%)$, and 1 patient (1 foot) had a poor score (5\%) (El-Shazly et al., 2010).

In the study of Komatsu the American Orthopaedic Foot and Ankle Society (AOFAS)ankle-hind foot pain score improved significantly from $18.0 \pm 6.3$ points preoperatively to $36.0 \pm 5.2$ points at 2 years after surgery (Komatsu, Takao, \& Innami, 2011). 
In the study of Radwan et al that compared endoscopic plantar fasciotomy versus extracorporeal shock wave, the endoscopic plantar fasciotomy group improvement of pain according to Modified American Orthopaedic Foot and Ankle Society (AOFAS) ankle- hind foot score from 0(0-20) to 30(20-30) was achieved between 3 weeks to 3 months and was maintained at the one year follow up. The results were the same for the other group (Radwan, Mansour, \& Badawy, 2012). Moreover, Bader et al evaluated the functional outcome of endoscopic plantar fasciotomy in 48 patients (56 feet). They reported that pain resolved completely in 37 feet, decreased in 11 feet, and increased in one foot (Bader et al., 2012).

\section{Function and Activity Limitation}

In our study, the modified American Orthopaedic Foot and Ankle Society (AOFAS) ankle- hind foot score for activity of daily living improved from a mean of $4 \pm 0$ points pre-operatively to $9.85 \pm 0.671$ post-operatively ranging from 7 to 10 points.

In the study of Othman et al., pre-operative limitation of activities was severe in $64.7 \%$ of patients (11 patients), and $35.3 \%$ of patients (6 patients) had moderate limitation of activities. Post operatively $58.8 \%$ of patients (10 patients) had no limitation of activities, and $35.3 \%$ of patients (6 patients) had minimal limitation of activities. Only one patient had moderate limitation of activities (Othman \& Ragab, 2010).

In the study of Radwan et al, the function and activities improved according to American Orthopaedic Foot and Ankle Society (AOFAS) ankle- hind foot score from a mean of 4 points to 7 points between 3 weeks to 3 months and was maintained at the one year follow up (Radwan et al., 2012).

\subsection{Maximum Walking Distance}

In our study, the American Orthopaedic Foot and Ankle Society (AOFAS) ankle- hind foot score for maximum walking distance improved from a mean of $1.10 \pm 1.021$ points ranging from 0 to 2 points preoperatively to $4.25 \pm 0.933$ points postoperatively ranging from 2 to 5.0 points.

In the study of Radwan et al, the maximum walking distance improved according to Modified American Orthopaedic Foot and Ankle Society (AOFAS) ankle- hind foot score from a mean of 4 points ranging from 2 to 4 points preoperatively to 5 points postoperatively ranging from 4 to 7 points at the one year follow up (Radwan et al., 2012).

\subsection{Patient Satisfaction}

At the end of the follow up period of our study, the modified American Orthopaedic Foot and Ankle Society (AOFAS) ankle- hind foot score for patient satisfaction was $14.25 \pm 3.35$ points. Two patients $(10 \%)$ were fairly satisfied with the results. One patient was poorly satisfied $(5 \%)$. She was a female patient, 65 years old, diabetic, who complained of wound infection. The rest of 17 patients $(85 \%)$ were satisfied with the results of endoscopic plantar fasciotomy.

In a review of 40 cases by Stone and Davies, $70 \%$ of the patients stated they would recommend the procedure to others with heel pain or would undergo the procedure again given the same choice (Stone \& Davies, 1996).

Stone and McClure reviewed 25 cases and found that $92 \%$ would recommend the procedure to others and $84 \%$ would do it again (Stone \& McClure, 1999).

In the study of Othman et al; fourteen patients $(82.3 \%)$ were completely satisfied, two patients $(11.8 \%)$ were satisfied with reservations, and one patient $(5.9 \%)$ was unsatisfied with the end result of endoscopic plantar fasciotomy (Othman \& Ragab, 2010).

\subsection{Return to Daily Activities}

At the end of the follow up period, the time elapsed from surgery to return to work was $2 \pm 0.32$ months ranging from 1 to 3 months. In the study of Othman et al; the average period before return to work or daily activities was 6 weeks (Othman \& Ragab, 2010). In the study of Komatsu et al, all patients returned to full athletic activities by a mean of $2.7 \pm 0.7$ months (Komatsu et al., 2011).

\subsection{Complications}

In this study, a 65 years old diabetic female patient complained of wound infection on the medial side of the wound at 3 weeks follow up. The infection significantly improved after 6 weeks with the use of antibiotics and frequent dressing. She could return to daily activities after 3 months, but with moderate pain that continued till the end of the study.

Five patients complained of moderate pain on the lateral side of the heel (generally presenting as pain of the calcaneal-cuboid and metatarsal-cuboid joints). At 4 months follow up two of them improved completely, and at 6 months the other three patients had daily mild lateral pain which was accepted by all the patients and the pain was too mild to affect their daily activities. 
No post-operative foot deformities or change in the arches were noted clinically or radiologically. In a series of 265 patients, Burke reported 34 complications, most involving lateral column pain. Most patients responded to post-operative treatments (Hake, 2000).

Urovitz et al studied the use of endoscopic plantar fasciotomy in the treatment of chronic heel pain that was unresponsive to conservative treatment in 55 patients. There were only 2 complications; both being superficial wound infections that resolved completely after 7 days of oral antibiotics. There were no postoperative foot deformities or major changes in the arches of those who had surgery (E. Urovitz \& A. Urovitz, 2007).

Othman et al, reported two complications in the patients, one had superficial wound infection that resolved completely after 5 days of oral antibiotics; the other had numbness in the area of medial side of the heel that was relieved completely after 6 weeks. No postoperative foot deformities or changes in the arches were noted clinically or radiologically in patients (Othman \& Ragab, 2010).

In the study of Bader et al.; there was one superficial infection, one third and fourth metatarsal stress fracture in the same patient, and transient lateral hindfoot pain in five patients (Bader et al., 2012).

\section{Conclusions}

Endoscopic plantar fasciotomy is a safe effective treatment of plantar fasciitis after failure of conservative treatment. It also offers several important advantages; minimal soft tissue dissection, excellent visualization of the plantar fascia, precision in transecting only the medial one third of the plantar fascia, minimal postoperative pain with early return to full weight bearing status. Visualization of the entire width of the plantar fascia is important to cut only the medial third. Endoscopic plantar fasciotomy late presentation does not mean bad results.

\section{Competing Interests Statement}

The authors declare that there is no conflict of interests regarding the publication of this paper.

\section{References}

Aldridge, T. (2004). Diagnosing heel pain in adults. Am Fam Physician, 70, 332-338.

Andreasen Struijk, L. N. S., Birn, H., Teglbjaerg, P. S., Haase, J., \& Struijk, J. J. (2010). Size and separability of the calcaneal and the medial and lateral plantar nerves in the distal tibial nerve. Anat. Sci. Int., 85(1), 13-22. https://doi.org/10.1007/s12565-009-0045-y

Bader, L., Park, K., Gu, Y., \& O'Malley, M. (2012). Functional outcome of endoscopic plantar fasciotomy. Foot Ankle Int., 33(1), 37-43. https://doi.org/10.3113/FAI.2012.0037

Barrett, S., \& Day, S. (1991). Endoscopic plantar fasciotomy for chronic plantar fasciitis/heel spur syndrome: Surgical technique- early clinical results. J Foot Surg, 30, 568-570.

Barrett, S., \& Day, S. (1993). Endoscopic plantar fasciotomy: Two portal endoscopic surgical techniquesClinical results of 65 procedures. J Foot Ankle Surg., 32, 248-56.

Barrett, S., Day, S., \& Pignetti, T. (1995). Endoscopic plantar fasciotomy: A multi-surgeon prospective analysis of 652 cases. J Foot Ankle Surg., 34, 400-406. https://doi.org/10.1016/S1067-2516(09)80011-2

Baxter, D., \& Pfeffer, G. (1992). Treatment of Chronic Heel Pain by Surgical Release of the First Branch of the Lateral Plantar Nerve. Clin Orthop Relat Res., 279, 229-36. https://doi.org/10.1097/00003086-19920600000029

Baxter, D., \& Pfeffer, G. (1992). Treatment of Chronic Heel Pain by Surgical Release of the First Branch of the Lateral Plantar Nerve. Clin Orthop Relat Res., 279, 229-236. https://doi.org/10.1097/00003086-19920600000029

Baxter, D., \& Thigpen, C. (1984). Heel Pain-Operative Results. Foot Ankle Int., 5(1), 16-25. https://doi.org/10.1177/107110078400500103

Bazaz, R., \& Ferkel, R. (2007). Results of endoscopic plantar fascia release. Foot Ankle Int., 28, 549-56. https://doi.org/10.3113/FAI.2007.0549

Blanco, C. E., Leon, H. O., \& Guthrie, T. B. (2001). Endoscopic treatment of calcaneal spur syndrome: A comprehensive technique. Arthroscopy, 17(5), 517-22. https://doi.org/10.1053/jars.2001.24065

Brekke, M., \& Green, D. (1998). Retrospective analysis of minimal incision, endoscopic, and open procedures for heel spur syndrome. J Am Pod. Med Assoc., 88, 64-72.

Buchbinder, R. (2004). Plantar fasciitis. N. Engl. J. Med., 350(21), 2159-66. https://doi.org/10.1056/NEJMcp032745

Cheung, J., \& Zhang, M. (2006). Consequences of Partial and Total Plantar Fascia Release: A Finite Element 
Study. Foot Ankle Int., 27(2), 125-132. https://doi.org/10.1177/107110070602700210

Cole, C., Seto, C., Gazewood, J., Charles, C., \& John, G. (1995). Plantar fasciitis: Evidence-Based Review of Diagnosis and Therapy. Am Fam Physician, 72(11), 2237-2242.

Dailey, J. (1991). Differential diagnosis and treatment of heel pain. Clin Pod. Med Surg., 8(1), 153-166.

Davis, P., Severud, E., \& Baxter, D. E. (1994). Painful heel syndrome: results of nonoperative treatment. Foot Ankle Int., 15(10), 531-535. https://doi.org/10.1177/107110079401501002

DiMarcangelo, M., \& Yu, T. (1997). Diagnostic imaging of heel pain and plantar fasciitis. cCin Pod. Med Surg., 14(2), 281-301.

DuVries, H. (1957). Heel Spur (Calcaneal Spur). Arch Surg., 74, 536-542. https://doi.org/10.1001/archsurg.1957.01280100054008

El-Shazly, O., El-Hilaly, R. A., Abou El-Soud, M. M., \& El-Sayed, M. N. M. A. (2010). Endoscopic plantar fascia release by hooked soft-tissue electrode after failed shock wave therapy. J. Arthrosc. Relat. Surg., 26(9), 1241-1245. https://doi.org/10.1016/j.arthro.2010.01.026

Furey, J. (1975). Plantar fasciitis. The painful heel syndrome. J Bone Jt. Surg Am., 57(5), 672-673.

Gill, L. G. M. K. (1996). Outcome of nonsurgical treatment for plantar fasciitis. Foot Ankle Int., 17(9), 527-532. https://doi.org/10.1177/107110079601700903

Hake, D. H. (2000). Endoscopic plantar fasciotomy: A minimally traumatic procedure for chronic plantar fasciitis. Ochsner J., 2, 175-178.

Hassab, H., \& El-Sherif, A. (1974). Drilling of the os calcis for painful heel with calcanean spur. Acta orthop scand, 45(4), 152-157. https://doi.org/10.3109/17453677408989133

Ibrahim, T., Beiri, A., Azzabi, M., Best, A. J., Taylor, G. J., \& Menon, D. K. (2007). Reliability and validity of the subjective component of the American Orthopaedic Foot and Ankle Society clinical rating scales. $J$. Foot Ankle Surg., 46(2), 65-74. https://doi.org/10.1053/j.jfas.2006.12.002

Kenzora, J. (1987). The painful heel syndrome: an entrapment neuropathy. Bull. Hosp. Jt. Dis. Orthop. Inst., 47(2), 178-189.

Kinley, S., Frascone, S., Calderone, D., Wertheimer, S., Squire, M., \& Wiseman, F. (1993). Endoscopic plantar fasciotomy versus traditional open heel spur surgery: a prospective study. J Foot Ankle Surg., 32, 595-603.

Komatsu, F., Takao, M., \& Innami, K. (2011). Endoscopic surgery for plantar fasciitis: application of a deepfascial approach. J. Arthrosc. Relat. Surg, 27(8), 1105-1109. https://doi.org/10.1016/j.arthro.2011.02.037

Kulkarni, R. S. (2004). Conservative treatment of plantar fasciitis. Indian Journal of Orthopaedics. 38(2), 121.

Labib, S., Gould, J., Rodriguez-del-Rio, F., \& Lyman, S. (2002). Heel pain triad (HPT): The combination of plantar fasciitis, posterior tibial tendon dysfunction and tarsal tunnel syndrome. Foot Ankle Int., 23, 212-220. https://doi.org/10.1177/107110070202300305

Mario, R., \& Roxas, M. (2005). Plantar Fasciitis: Diagnosis and Therapeutic Considerations. Altern. Med. Rev., 10(2), 83-93.

Miyamoto, W., Takao, M., \& Uchio, Y. (2010). Calcaneal osteotomy for the treatment of plantar fasciitis. Arch Orthop Trauma Surg, 130(2), 151-154. https://doi.org/10.1007/s00402-009-0879-8

Nery, C., Raduan, F., Mansur, N., Baunfeld, D., Del Buono, A., \& Maffulli, A. (2013). Endoscopic approach for plantar fasciopathy: a long-term retrospective study. Int. Orthop., 37(6), 1151-1156. https://doi.org/10.1007/s00264-013-1847-z

Niki, H., Aoki, H., Inokuchi, S., Ozeki, S., Kinoshita, M., Kura, H., et al. (2005). Development and reliability of a standard rating system for outcome measurement of foot and ankle disorders I: development of standard rating system. J. Orthop. Sci., 10(5), 457-65. https://doi.org/10.1007/s00776-005-0936-2

O'Malley, M, Page, A, \& Cook, R. (2000). Endoscopic plantar fasciotomy for chronic heel pain. Foot Ankle Int., 21, 505-10. https://doi.org/10.1177/107110070002100610

Othman, A. M. A., \& Ragab, E. M. (2010). Endoscopic plantar fasciotomy versus extracorporeal shock wave therapy for treatment of chronic plantar fasciitis. Arch. Orthop. Trauma Surg., 130(11), 1343-1347. https://doi.org/10.1007/s00402-009-1034-2

Ozdemir, H., Yilmaz, E., Murat, A., Karakurt, L., \& Kursad-Poyraz, A. O. E. (2005). Sonographic evaluation of plantar fasciitis and relation to body mass index. Eur. J. Radiol., 54, 443-447. https://doi.org/10.1016/j.ejrad.2004.09.004 
Parrett, S. (2002). A closer Look at endoscopic plantar Fasciotomy. Pod. Today, 15(5), 38-44.

Prichasuk, S., \& Subhadrabandhu, T. (1994). The relationship of pes planus and calcaneal spur to plantar heel pain. Clin Orthop, 306, 192-196.

Radwan, Y., Mansour, A., \& Badawy, W. (2012). Resistant planter fasciopathy: shock wave versus endoscopic planter fascial release. Int. Orthop., 36, 2147-256. https://doi.org/10.1007/s00264-012-1608-4

Rano, J., Fallat, L., \& Savoy-Moore, R. (2001). Correlation of heel pain with body mass index and other characteristics of heel pain. J Foot Ankle Surg., 40, 351-356. https://doi.org/10.1016/S1067-2516(01)800028

Resnick, R., Hudgins, L., Buschmann, W., Kummer, F., \& Jahss, M. (1999). Analysis of the heel pad fat in rheumatoid arthritis. Foot Ankle Int., 20, 481-484. https://doi.org/10.1177/107110079902000803

Riddle, D., Pulisic, M., Pidcoe, P., \& Johnson, R. (2003). Risk factors for plantar fasciitis: a matched casecontrol study. J Bone Jt. Surg Am., 85, 872-877.

Rome, K. (2005). Heel pain: diagnosis and management. Pod. Now, 8(4), 51-58.

Santini, S., Rebeccato, A., Schiavon, R., \& Nogarin, L. (2003). Percutaneous drilling for chronic heel pain. $J$ Foot Ankle Surg., 42(5), 296-301. https://doi.org/10.1016/j.jfas.2003.08.002

Stone, P., \& Davies, J. (1996). Retrospective review of endoscopic plantar fasciotomy- 1992 through 1994. J Am Pod. Med Assoc., 86, 414-420.

Stone, P., \& McClure, L. (1999). Retrospective review of endoscopoic plantar fasciotomy-1994 through 1997. $J$ Am Pod. Med Assoc., 89, 89-93.

Taunton, J., Ryan, M., Clement, D., McKenzie, D., Lloyd-Smith, D., \& Zumbo, B. (2002). A retrospective casecontrol analysis of 2002 running injuries. Br J Sport. Med., 36, 101.

Toomey, E. P. (2009). Plantar heel pain. Foot Ankle Clin., 14(2), 229-245. https://doi.org/10.1016/j.fcl.2009.02.001

Tweed, J., Barnes, M., Allen, M., \& Campbell, J. (2009). Biomechanical Consequences of Total Plantar Fasciotomy. J Am Pod. Med Assoc, 99(5), 422-430.

Urovitz, E., \& Urovitz, A. (2008). Endoscopic planter fasciotomy in the treatment of chronic heel pain. Can $J$ Surg., 51(4), 281-283.

Young, C. C., \& Rutherford, D. S. N. M. (2001). Treatment of plantar fasciitis. Am Fam Physician, 63(3), 467$74,477-478$.

\section{Copyrights}

Copyright for this article is retained by the author(s), with first publication rights granted to the journal.

This is an open-access article distributed under the terms and conditions of the Creative Commons Attribution license (http://creativecommons.org/licenses/by/4.0/). 